\title{
Informática e educação no ensino superior: reflexões sobre a relação com o saber de estu- dantes de cursos da área de computação
}

Title: Informatics and higher education: reflections on education and the relationship with students' knowledge in computer sciences

\author{
Elaine Rafaela Neves de \\ Freitas \\ Universidade Vale do Rio \\ Doce - Governador Valadares \\ $-\mathrm{MG}$ \\ laninha22_gv@hotmail.com
}

\author{
Maria Gabriela Parenti \\ Bicalho \\ Universidade Vale do Rio \\ Doce - Governador Vala- \\ dares - MG \\ gpbicalho1@uol.com.br
}

\author{
Maria Celeste Reis Fer- \\ nandes de Souza \\ Universidade Vale do Rio \\ Doce - Governador Vala- \\ dares - MG \\ celeste.br@gmail.com
}

\author{
Cristiane Mendes Netto \\ Universidade Vale do Rio \\ Doce - Governador Vala- \\ dares - MG \\ cristiane@univale.br
}

Resumo Este artigo apresenta resultados de uma investigação que buscou compreender as relações que estudantes do Ensino Superior estabelecem com o saber a partir da incorporação das Tecnologias de Informação e Comunicação - TIC em sua vida acadêmica. O referencial teórico e metodológico ancorase em estudos do campo da Sociologia da Educação, de modo especial a teoria da relação com o saber de Bernard Charlot. O campo de pesquisa é uma instituição de Ensino Superior comunitária e os sujeitos são 106 estudantes dos cursos de Sistemas de Informação e Ciência da Computação. Para a coleta de dados utilizou-se o inventário de saberes, técnica de pesquisa usualmente realizada nas pesquisas sobre a relação com o saber. A análise dos dados permite concluir que os estudantes, em sua grande maioria, utilizam em suas aprendizagens as TIC, especialmente os recursos da internet. Cabe destacar que essa utilização é feita, também, em sua maioria, por iniciativa própria em detrimento da solicitação docente o que coloca esses estudantes na condição de protagonistas. Entretanto, essa condição apresenta para esses estudantes dilemas que são marcados pela ampliação das possibilidades de aprendizagem, pela facilidade de dispersão, pela necessidade de auto disciplina e pela facilidade do plágio na produção dos trabalhos acadêmicos.

Palavras Chave: Ensino superior; Relação com o saber; Tecnologias de Informação e Comunicação.

\begin{abstract}
This paper presents the results of an investigation which tried to understand the relationships established between Higher Education's students and knowledge, taking as a standpoint the incorporation of Information and Communication Technology - ICT in their academic activities. The methodological and theoretical referential are based on the field studies of sociology of education, especially the theory of the relationship with knowledge of Bernard Charlot. The research was performed in a private institution of Higher Education, and the subjects were 106 undergraduate students of the courses of Computer Science. The technique used for the data collection was the inventory of knowledge, a technique of research usually held in researches of relationships with knowledge. The data analyzed allow us to conclude that most of the students use the ICTs in their learning, especially the internet resources. It's important to point out that this mobilization is also made by the students' own initiative instead of teacher's requirement, which puts these students in a protagonist's condition. However, this condition creates dilemmas which are marked by the learning possibilities, attention span, and necessity of self-discipline and the easiness of plagiarism in the production of academic papers for these students.
\end{abstract}

Keywords: Higher Education; Relation to Knowledge, Information and Communication Technologies. 


\section{Introdução}

Temos assistido na contemporaneidade a incorporação cada vez maior das Tecnologias de Informação e Comunicação (TIC), principalmente as digitais, aos nossos modos de vida que encontram-se cada vez mais "dependentes" dessas ferramentas. Tal incorporação repercute em nossas ações, modos de pensar, modos de conhecer, modos de comunicar e em nossas relações com o outro, com o mundo e com o conhecimento. O campo da Educação não fica alheio a essa incorporação como mostram os estudos de Belloni [1], Levy [2], Vigneron [3], Picanço [4].

No Ensino Superior a incorporação dessas tecnologias tem sido objeto de investigação vinculada, à expansão da oferta de cursos de graduação na modalidade em Educação a Distância - EaD [5] e em pesquisas que se voltam para os efeitos dessa incorporação sobre o ensino presencial, nos diferentes cursos de graduação (Amen e Nunes [19]; Costa et al. [20]; Peres, Meira e Leite [21]; Peres et al [22]; Santa Rosa e Struchiner [23].

É no sentido de contribuir para a ampliação das discussões sobre o uso da TIC no Ensino Superior, que compartilhamos os resultados de uma investigação na qual nossos questionamentos dirigiram-se especificamente para as possibilidades de estabelecimento de novas relações com o saber a partir da incorporação das TIC no Ensino Superior.

Nessa perspectiva, apresentamos resultados de uma investigação que se propôs compreender as relações que estudantes do Ensino Superior estabelecem com o saber a partir da incorporação das TIC em sua vida acadêmica. O campo de investigação é uma instituição comunitária de Ensino Superior e os sujeitos são 106 estudantes dos cursos de Ciência da Computação e Sistemas de Informação.

A abordagem metodológica da investigação, de cunho qualitativo, é inspirada nos modos como Bernard Charlot $[6,7,8,9]$ realizou suas investigações ao nos propor a "relação com o saber", como aporte teórico e metodológico.

$\mathrm{O}$ artigo encontra-se dividido em quatro seções: na primeira seção situamos o aporte teórico e metodológico da investigação ampliando as possibilidades de diálogo no campo da informática e educação, tendo como referência o constructo teórico proposto por Charlot; na segunda seção apresentamos a metodologia utilizada na realização da pesquisa; na terceira seção discutimos os resultados obtidos e na última seção argumentamos, em nossas considerações finais, sobre os desafios que as relações com o saber dos estudantes no contexto de utilização das TIC apresentam para a prática docente no Ensino Superior.

\section{Referencial Teórico}

As reflexões apresentadas neste artigo tiveram origem na realização de pesquisas sobre a relação com o saber de estudantes do ensino superior de Bicalho [10, 11,12], e de modo especial quando nos interessamos pelos processos de ensinar e aprender nos cursos de graduação da área de computação de Souza [13]. Observamos, durante a coleta de dados de uma investigação que analisou a relação com o saber estabelecida por estudantes de 24 cursos de graduação de diferentes áreas do conhecimento, que os estudantes e professores de cursos na área de computação (Sistemas de Informação e Ciência da Computação) utilizam durante as aulas com maior frequência, e muitas vezes de modo prioritário, os recursos dos computadores e da internet. A partir dessa constatação, passamos a nos questionar sobre as relações com o saber dos estudantes, nesse contexto. Estamos nos referindo, especificamente, a dois aspectos:

- a utilização do computador em sala de aula, substituindo papel e lápis, com o objetivo de tomar notas e realizar trabalhos, levando os estudantes a habituarem-se a "escrever no computador" e "pensar no computador".

- a utilização de recursos da internet, que possibilitam o acesso simultâneo a fontes diversas com a lógica do hipertexto, dando suporte ao texto produzido pelos estudantes para cumprir diferentes demandas acadêmicas (trabalhos, avaliações).

No campo da educação, a perspectiva construcionista ${ }^{1}$ tem sido, de modo geral, a adotada como abordagem norteadora nas pesquisas que investigam a informática aplicada à educação. Tal abordagem se orienta para "o desenvolvimento e o uso da tecnologia, em especial, do computador, na criação de ambientes educacionais" [14]. As pesquisas que se realizam com o construcionismo como pano de fundo, têm como foco de seus estudos os aspectos cognitivos. Compartilham, portanto o pressuposto de que o conhecimento é construído por um sujeito ativo -operatório - na interação com esta ferramenta em um processo de construção e reconstrução de estruturas mentais. Inspirado em uma abordagem construtivista o construcionismo "é tanto uma teoria de aprendizado quanto uma estratégia para a educação [14].

Ainda que consideremos a riqueza desta abordagem, mobilizamos nesta pesquisa outra perspectiva de análise ao adotarmos a categoria da relação com o saber como propõe Bernard Charlot, estabelecendo um diálogo com o campo da Sociologia da Educação. Diferentemente de um sujeito operatório, esse autor propõe a compreensão do sujeito como, ao mesmo tempo, e inteiramente, um ser humano, um ser social e um ser singular. Um ser de

\footnotetext{
${ }^{1} \mathrm{O}$ construcionismo origina-se a partir de um conjunto de ideias do matemático Seymour Papert, na década de 60, discípulo e colaborador de Piaget e foi influenciado pelos conceitos de Inteligência Artificial que floresciam no MIT (Massachusetts Institute of Technology) (MALTEMPI, 2004).
} 
desejo em um mundo compartilhado com outros sujeitos; que ocupa uma posição social cuja primeira instância é a família e atribui sentidos e significados singulares a si próprio e ao mundo, na construção de uma história singular. Para esse sujeito, aprender é uma necessidade que marca sua presença em um mundo produtor de saberes. Essa atividade é central no processo de construção do homem, que envolve tornar-se um membro da espécie humana (hominizar-se), tornar-se um ser humano único (singularizar-se) e tornar-se membro de uma comunidade, ocupando nela um lugar (socializar-se). Através da educação produz-se a si mesmo e é produzido pelo mundo. Portanto, o sujeito e sua história são sempre totalmente sociais e totalmente singulares, e o pertencimento a uma classe social é interpretado de maneira ativa pelo indivíduo, na construção de uma história da qual é sujeito.

Assim, ao propormos como questão norteadora desta investigação, "como se configuram as relações que estudantes do Ensino Superior estabelecem com o saber a partir da incorporação das TIC em sala de aula" procuramos apreender as relações com o conhecimento mediadas por essas tecnologias, afastando-nos de uma perspectiva estritamente cognitiva, para compreender essas relações em uma rede de conexões do sujeito, conectado a si mesmo e ao mundo: sujeito ao mesmo tempo social e singular.

Ao problematizar o fracasso escolar como um "objeto de pesquisa inencontrável" e na tentativa de lançar outros olhares sobre estudantes em situação de fracasso escolar, explicitando os limites das teorizações que buscavam compreender tal situação, Charlot [7] propõe a categoria da "relação com o saber" em uma perspectiva sociológica que considere o sujeito, pois, segundo o autor, não há saber e não há sujeito de saber fora de uma relação com o saber. Essa proposta teórica tem sido utilizada por diversos/as pesquisadores/as na compreensão de diferentes fenômenos no campo educacional como, por exemplo, as relações dos jovens com o saber [8]; a relação com o saber de alunas do curso de Pedagogia [10],[11]; a relação com o saber na aprendizagem matemática [15].

Ao mobilizarmos a categoria de análise da relação com o saber, nesta investigação, compreendemos que essa relação se estabelece por um sujeito singular e se constrói em suas relações "com o mundo, com ele mesmo e com os outros. É relação com o mundo como conjunto de significados, mas também como espaço de atividades, e se inscreve no tempo". [8].

Assim, o sujeito está no mundo (com ele mesmo e com os outros). Os cenários desse mundo com o avanço da tecnologia são marcados por movimento, velocidade, ritmo acelerado, interações, conexões múltiplas, estabelecimento de relações em diferentes tempos e espaços. Conforme Levy [16] as modificações advindas do desenvolvimento tecnológico convergem para a constituição de um novo meio de comunicação, de pensamento e de trabalho para as sociedades humanas. Seguindo o que afirma Levy [17] não podemos desconsiderar do cenário das investigações sobre educação três constatações: a velocidade de surgimento e de renovação dos saberes; a nova natureza do trabalho, onde trabalhar quer dizer, cada vez mais, aprender, transmitir saberes e produzir conhecimentos e a constatação de que as tecnologias amplificam, exteriorizam e modificam numerosas funções cognitivas humanas.

Neste sentido, estar com ele mesmo e com o outro, nesse mundo, é para o sujeito adentrar em um espaço de atividades cada vez mais amplo e que não se circunscreve à sala de aula e ao tempo marcadamente cronológico. Há, portanto, uma simultaneidade de tempos e espaços que adentra a universidade e marca os diferentes processos do cotidiano do ensino superior.

Não se concebe mais uma educação que não ofereça a estudantes a possibilidade de conexão a esse mundo, como já anunciava Belloni [1] há mais de uma década.

O papel da educação na sociedade - a definição de suas finalidades maiores - está se transformando e suas estratégias vêm sendo modificadas de modo a responder às novas demandas, notadamente com a introdução de meios técnicos e de uma flexibilidade maior quanto às condições de acesso a currículos, metodologias e materiais. [1]

Neste contexto, a tecnologia não fica mais restrita a laboratórios de informática, tornando-se condição para o funcionamento de cursos de graduação. Trazida por estudantes, está na sala de aula: nos celulares com seus inúmeros recursos (da comunicação telefônica ao mundo virtual; do registro em fotos à possibilidade de vídeos e filmagens), nos computadores e tablets com suas infinitas possibilidades de acesso a outros mundos (real e virtuais).

É, portanto, nesse mundo em movimento, com esta simultaneidade de espaços e tempos que o ensino superior se confronta. São produzidas desse modo, no espaço da universidade, outras relações, conexões, aprendizagens, significações que tensionam modos tradicionais de organizar e compreender a educação.

A universidade é reconhecida como espaço de produção de conhecimentos. Bicudo e Borba [18] atentam para o fato da chegada à universidade de gerações nascidas, criadas e impregnadas do contato com textos marcados pela comunicação via internet e hipermidiáticos. Entender essa geração que já traz uma cultura hipermidiática, é, segundo os autores, portanto fundamental para compreender o próprio conhecimento produzido no espaço da universidade.

Os autores argumentam que a entrada dessa geração na escola tem produzido transformações em nosso "cotidiano em universidades com acesso à internet, lançando 
questionamentos sobre o que deve ser considerado aprendizagem e sobre o que deve ser aprendido em geral" [18].

No ensino superior, o estudante deve confrontar-se com a possibilidade de ampliação de acesso ao conhecimento e com a perspectiva da produção do conhecimento. Vê-se, portanto, diante do desafio de um saber que não se reduz a repetição de clássicos ou a uma "informação armazenada, estocada" [8], ou como algo objetivado, que existe por si só - "o saber", mas um saber que se coloca sempre "em relação".

Esta será uma relação de um sujeito com seu mundo, é relação com o mundo e com uma forma de apropriação do mundo: toda relação com o saber apresenta uma dimensão epistêmica. Mas qualquer relação com o saber comporta também uma dimensão de identidade: aprender faz sentido por referencia à história do sujeito, às suas expectativas, às suas referencias, à sua concepção da vida, às suas relações com os outros, à imagem que tem de si e à que quer dar de si aos outros [8].

Estamos nos valendo dessa categoria "relação com o saber" para pensar o saber como produzido sempre em relações, portanto nas práticas nas quais as pessoas se envolvem. Em um mundo informatizado e conectado, a relação com o saber é marcada por uma simultaneidade de tempos e espaços e, nesse sentido, as TIC, "estão fortemente presentes na vida dos graduandos" [15], nas diferentes práticas sociais nas quais se envolvem. Ao serem interrogados sobre a presença das tecnologias na escola estudantes afirmam, em sua maioria, "utilizar hipertextos digitais para pesquisas nos mais variados campos do conhecimento, principalmente, visando à elaboração de trabalhos exigidos pela universidade". [15]

É nessa perspectiva de que o saber não existe fora de uma relação, que mobilizamos a categoria "relação com o saber" para compreender as relações que estudantes do Ensino Superior de cursos da área de computação estabelecem com o saber a partir da incorporação em sala de aula das Tecnologias de Informação e Comunicação.

\section{Metodologia}

Os dados aqui apresentados foram coletados por meio do inventário de saberes, proposto por Bernard Charlot. Em sua versão original, esse instrumento de coleta de dados consiste na apresentação da demanda da produção de um texto a partir das seguintes questões: "Desde que nasci, aprendi muitas coisas, em casa, na rua, na escola e em outros lugares...O quê? Com quem? O que é importante para mim nisso tudo? E agora, o que eu espero?' $[6]^{1}$.

1 "Depuis que je suis né j'ai appris plein de choses, chez moi, dans la cité, à l'école et ailleurs... Quoi? Avec qui? Qu'est-ce qui est important
Tradicionalmente, em pesquisas realizadas tendo como referência os estudos de Charlot, esse instrumento é respondido em contatos presenciais com a equipe de pesquisa. Em nossa proposta atual, o contato com os sujeitos da pesquisa e a resposta ao instrumento foi realizado por meio de formulário de dados via web disponibilizado no sítio eletrônico da instituição, incorporando deste modo o uso da tecnologia na coleta de dados.

O texto do inventário também foi adaptado para a discussão das tecnologias da informação e comunicação. Assim, os sujeitos foram convidados a inventariar as aprendizagens efetivadas no uso das TIC a partir das seguintes questões: "Conectados ao mundo da tecnologia temos aprendido muitas coisas. Como você se conecta a este mundo? O que aprende com ele? Como este mundo da tecnologia é utilizado por você, em suas aprendizagens escolares? Existem disciplinas específicas para as quais você utiliza estas tecnologias? Isto acontece por iniciativa própria ou a pedido do/a professor/a?".

Os inventários de saberes foram aplicados em todas as turmas de todos os períodos dos cursos de Ciência da Computação e Sistemas de Informação, que se encontravam em oferta durante a realização da coleta de dados (agosto a novembro de 2011) e foi respondido voluntariamente por 106 estudantes: 48 do curso de Ciência da Computação e 58 do curso de Sistemas de Informação. Nesse conjunto temos respostas de 98 homens e 8 mulheres. O quadro abaixo mostra a distribuição dos sujeitos da pesquisa por curso, período e sexo.

\begin{tabular}{|c|c|c|}
\hline \multicolumn{3}{|c|}{ Ciência da Computação: 48 alunos } \\
\hline Distribuição por período & \multicolumn{2}{|c|}{ Distribuição por sexo } \\
\cline { 2 - 3 } & Mulher & Homem \\
\hline $1^{\circ}$ Período & 02 & 19 \\
\hline $5^{\circ}$ Período & 01 & 16 \\
\hline $7^{\circ}$ Período & 00 & 10 \\
\hline \multicolumn{2}{|c|}{ Sistemas de Informação: 58 alunos } \\
\hline Distribuição por período & Distribuição por sexo \\
\cline { 2 - 3 } & Mulher & Homem \\
\hline $1^{\circ}$ Período & 02 & 25 \\
\hline $2^{\circ}$ Período & 01 & 17 \\
\hline $7^{\circ}$ Período & 01 & 12 \\
\hline
\end{tabular}

Tabela 1: Número de estudantes do curso de Ciência da Computação e Sistemas de Informação que participaram da pesquisa distribuídos por período e sexo.

A análise dos inventários produzidos pelos estudantes possibilitou o conhecimento acerca da utilização que eles fazem das novas tecnologias da informação e da comunicação. Esses resultados são apresentados a seguir, considerando o conjunto das respostas dos estudantes dos dois cursos.

pour moi dans tout ça? Et maintenant, qu'est-ce que j'attends?" (CHARLOT,1999, p.7) 


\section{Resultados}

Com a realização da pesquisa, foram obtidos resultados quantitativos e qualitativos. Os dados quantitativos, expressos nos gráficos, referem-se à frequência da utilização das diferentes tecnologias da informação e da comunicação, aos diferentes tipos de atividades realizadas com as TIC e se essas atividades são realizadas por uma demanda dos professores, por iniciativa dos estudantes ou ambas as situações. Os dados qualitativos são apresentados com extratos dos textos produzidos pelos estudantes ao responderem às questões dos inventários de saberes, e expressam os significados que os mesmos atribuem à utilização que fazem das TIC em seus cursos.

\section{1 - Tecnologias utilizadas ${ }^{1}$}

Um primeiro conjunto de informações refere-se às tecnologias utilizadas pelos estudantes. Ao responder aos inventários, a maior parte dos sujeitos de pesquisa citou mais de um recurso tecnológico. Apresentamos, portanto, por quantos estudantes cada recurso foi citado. Dos 106 estudantes sujeitos da pesquisa, 38 citaram a internet como tecnologia utilizada, o que corresponde a $35,85 \%$ do total. A segunda tecnologia mais citada foi o computador, lembrado por 31 estudantes, ou seja, $29,25 \%$ do total. O telefone celular foi citado por 17 estudantes, o que equivale a $16,04 \%$ do total. Por sua vez, a televisão foi citada por 5 estudantes, o que corresponde a $4.72 \%$ do total. Três (3) estudantes utilizaram a expressão "redes sociais" para indicar a tecnologia utilizada, correspondendo a $2,83 \%$ dos estudantes pesquisados. Outras tecnologias como aparelhos eletrônicos, rádio, tablets, pendrive e software foram citadas por no máximo três estudantes, 2, 83\%. Uma parcela dos estudantes entrevistados utilizaram o termo genérico "tecnologias" ou "tecnologias da informação" em suas respostas, não especificando nenhum recurso. Enquadram-se nessa situação 26 estudantes, ou seja, $24,53 \%$ do total.

A figura 1, a seguir, permite a visualização da frequência de citação das tecnologias.

A análise dos inventários mostrou, portanto, que os estudantes utilizam diferentes tecnologias para se conectar ao mundo, com preponderância da internet. Mesmo nos inventários que não citaram diretamente esse recurso, podemos inferir o acesso à internet. Por exemplo, o computador, as redes sociais e os telefones celulares - citados pelos estudantes como tecnologias utilizadas, podem estar relacionados com o uso da internet.

\footnotetext{
${ }^{1}$ Utilizamos os termos empregados pelos estudantes em seus inventários ao responderem às questões relativas às tecnologias empregadas.
}

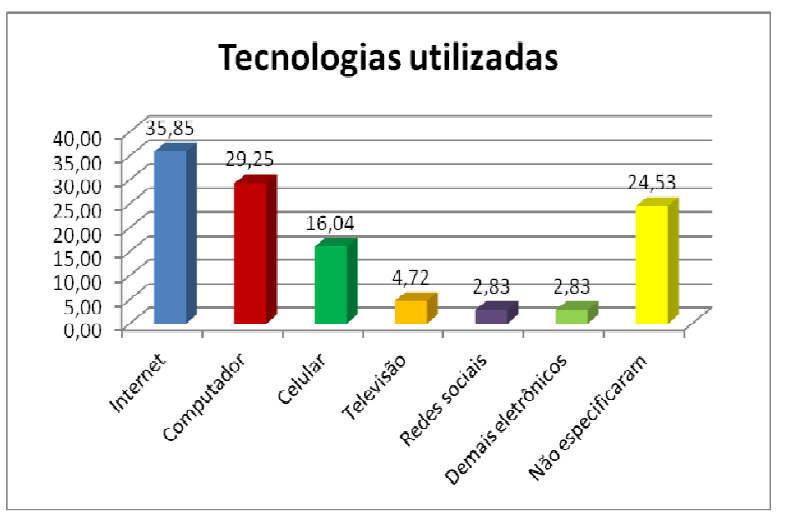

Figura 1:Gráfico representando as tecnologias utilizadas que foram citadas pelos estudantes

As declarações a seguir, identificadas nos textos produzidos pelos estudantes, revelam a importância atribuída por eles à internet como ferramenta de comunicação, informação e busca de conhecimento acadêmico.

"No mundo de hoje a internet é um dos meios de comunicação mais usado (...) a internet é a melhor invenção feita pelo homem. (...) Essas pesquisas são realizadas através da internet para várias disciplinas pois a internet abrange assuntos diversos”.(estudante 19, masculino, 18 anos,curso Ciência da Computação)

"A partir da internet, olhando os sites de noticias, vendo jornal, aprendo muitas coisas do dia-a-dia, na internet tem muitas coisas que podem ser muito úteis, muitas coisas que às vezes não sabemos podemos pesquisar e achar a resposta”. (estudante 13, masculino, 18 anos, curso Ciência da Computação)

"Com as minhas pesquisas na internet, vejo muita coisa que já aconteceu de marcante no mundo, como as novas perspectivas de futuro em todos os lugares; muitas delas feitas como trabalhos escolares e acadêmicos; a internet ajuda e muito a reduzir o tempo de pesquisa e deixar tudo mais dinâmico e prático”.(estudante 19, masculino, 18 anos,curso Ciência da Computação).

"A internet é um dos melhores lugares em que achamos as respostas, tem as Bibliotecas também que ajudam muito, mas todos nós sabemos que a internet está sendo cada dia mais acessada”. (estudante 13, masculino, 18 anos, curso Ciência da Computação).

Assim, a internet é reconhecida pelos estudantes como fonte de pesquisas, na qual podem encontrar conhecimentos variados de maneira facilitada. Podemos dizer, portanto, que a internet é um recurso tecnológico largamente utilizado pelos estudantes, e que é considerada por eles um recurso que apresenta possibilidades amplas de acesso ao conhecimento de seus cursos. 


\section{2 - Iniciativa da utilização das tecnologias}

A análise dos inventários de saberes produzidos pelos estudantes permitiu conhecer também de quem é a iniciativa na utilização das TIC: dos professores ou dos estudantes. Nas respostas dos estudantes há preponderância dos que utilizam as TIC por iniciativa própria $(42,45 \%)$; $10,38 \%$ dos estudantes declararam utilizar as TIC em seus cursos por iniciativa do professor e $24,53 \%$ utilizam as tecnologias por iniciativa tanto do professor quanto própria. Um estudante atribuiu a iniciativa da utilização da tecnologia ao mercado de trabalho e $21,70 \%$ dos sujeitos pesquisados não abordaram essa questão. Os dados obtidos em relação à iniciativas de utilização das tecnologias são apresentados na Figura 2.

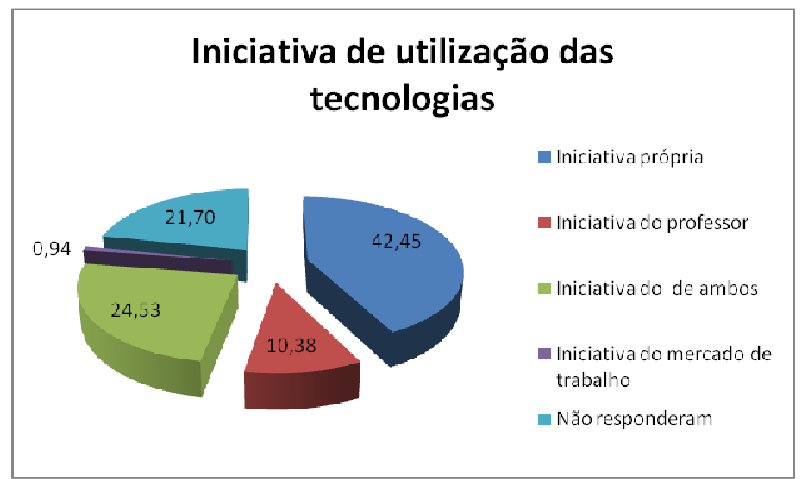

Figura 2:Gráfico representando as iniciativas de utilização das tecnologias

Assim, ao responderem ao questionamento sobre de quem era a iniciativa de utilização das novas tecnologias, os estudantes demonstram que atribuem primordialmente a si mesmos essa iniciativa, uma vez que somando-se as respostas que indicam iniciativa própria àquelas que indicam iniciativa própria e do professor temos $66,34 \%$. Essa observação permite refletir sobre a relação com o saber no contexto das novas tecnologias: a maior parte dos estudantes considera-se protagonista na busca da utilização dos recursos tecnológicos. Os extratos dos textos produzidos pelos estudantes como resposta aos inventários de saberes mostram que aspectos como liberdade de decisão, iniciativa e interesse são evocados por eles.

[As pesquisas feitas na internet] "muitas vezes acontece por minha própria iniciativa de diminuir a minha dificuldade e por sugestão e não por obrigação de professores". (estudante 19, masculino, 18 anos, curso Ciência da Computação).

"Utilizo a tecnologia em todas as disciplinas por uma questão de necessidade, mas também por interesse próprio". (estudante 44, masculino, 31 anos, curso de Sistemas de Informação).

\section{3 - Atividades realizadas com a utilização das} TIC

Ao produzir os inventários de saberes, os estudantes sujeitos da pesquisa apresentaram as atividades que realizam com as TIC. Também em relação a esse quesito, os sujeitos da pesquisa apresentaram, em sua maioria, mais de uma resposta. Os dados apresentados na figura três, portanto, indicam a frequência com a qual as diferentes atividades foram citadas pelos sujeitos da pesquisa. Grande parte deles, 49 estudantes, ou seja, 46,23\% do total falaram em "atividades acadêmicas"; o mesmo número de estudantes declarou utilizar as tecnologias para "pesquisa"; 12 estudantes (11,32\% do total) para "atualização"; o mesmo número (12 estudantes) indicou utilizar as TIC para "socialização", perfazendo igualmente $11,32 \%$ do total de respondentes; e nove estudantes $(8,49 \%$ do total) declararam utilizar as TIC para "atividades profissionais". As atividades "entretenimento" e "aprendizagem" foram citadas, cada uma, por 15 estudantes $(14.15 \%)$ do total de sujeitos da pesquisa, enquanto seis estudantes afirmaram "assistir a vídeos-aula", o que corresponde a 5,66\% do total de estudantes. Outras atividades (aplicação, curso online, enviar emails, programação e Downloads) foram citadas por 2, 83\% dos respondentes, e 19 estudantes $(17,92 \%)$ não indicaram as atividades realizadas.

Nesse sentido, conectar-se ao mundo com as tecnologias da informação e comunicação significa, para os estudantes dos cursos de Ciência da Computação e Sistemas de Informação, se comunicar, divertir, aprender, trabalhar e estabelecer relações interpessoais.

"Eu uso a internet em tudo, desde pesquisas escolares e extraescolares, conversar com amigos e até me divertir com games e vídeos muito loucos". (estudante 19, masculino, 18 anos, curso Ciência da Computação).

"Eu utilizo na área escolar de forma muito intensa já que faço um curso voltado para a área tecnológica: desde a execução de trabalhos a provas, comunicação em sala, saber as tendências e aprofundar nos assuntos pertinentes ao meu curso." (estudante 71, masculino, 18 anos, curso Sistemas de Informação).

"Utilizo este mundo da tecnologia para buscar novos conhecimentos, mais aprendizagem e etc." (estudante 52, masculino, 18 anos, curso Sistemas de Informação).

"Uso de várias formas, pra aprendizagem escolar é uma delas". (estudante 13, masculino, 18 anos, curso Ciência da Computação). 


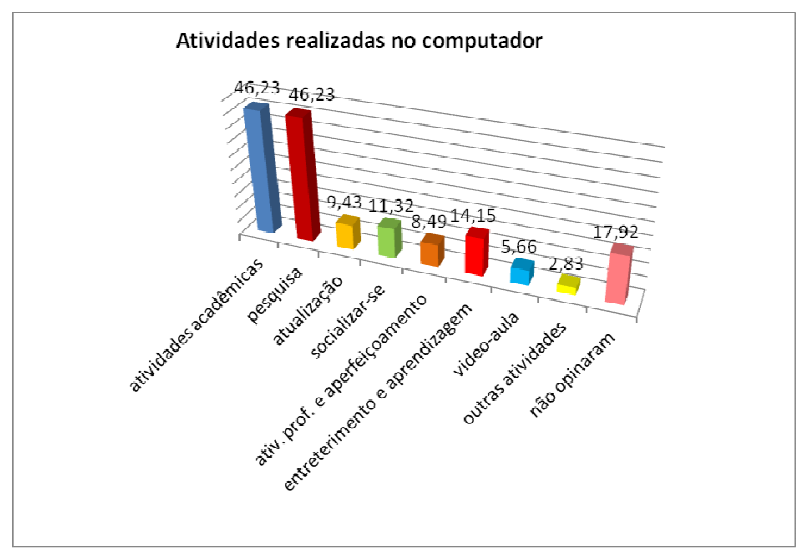

Figura 3:Gráfico representando as atividades realizadas no computador

"Utilizo para muitas coisas da vida, para viver". (estudante 62, masculino, 18 anos, curso Sistemas de Informação).

Essa multiplicidade de usos permite, por sua vez, uma diversidade de aprendizagens:

"Aprendo muitas coisas. desde notícias do mundo e do meio em que vivo até relações interpessoais, também coisas relacionadas ao meu trabalho já que atuo na área de tecnologia e outras relacionadas à universidade onde meu curso é voltado para essa área enfim muitas coisas que me ajudam nas mais diversas áreas e situações em que atuo e vivo diariamente. (estudante 71, masculino, 20 anos, Sistemas de Informação)

É interessante notar, nesses relatos, que as atividades de aprendizagem, trabalho, comunicação e entretenimento estão indistintamente relacionadas às tecnologias, ou seja, os estudantes estudam, trabalham e se divertem utilizando as mesmas ferramentas. Em se tratando de uma discussão do uso das TIC no Ensino Superior, constata-se a ampliação do uso da tecnologia no âmbito educacional, não mais restrita à aplicação para a elaboração de trabalhos acadêmicos na ferramenta word, elaboração de gráficos ou planilhas, sendo utilizada como fonte de pesquisa acadêmica.

O fato de utilizarem as TIC para múltiplas atividades pode, em alguns casos, significar dispersão, interferindo negativamente, segundo os relatos dos estudantes, nos processos de aprendizagem. Os recortes a seguir apresentam dilemas que se colocam para os estudantes com o uso das TIC. Se por um lado há uma abertura para inúmeras possibilidades de aprendizagem para além da sala de aula, a imersão no mundo da tecnologia parece requerer dos estudantes uma maior autodisciplina para evitar a dispersão na simultaneidade de espaços e tempos trazida pelas oportunidades de abertura de novas abas, janelas, navegadores etc.:

"Essa tecnologia às vezes atrapalha um pouco em ambientes de estudo, pois algumas vezes alunos perdem o foco da aula para navegar na internet e acabam no final prejudicando eles mesmos" (estudante 13, masculino, 35 anos, Ciência da Computação)

"A internet tem papel fundamental, através da pesquisa de soluções e download de ferramentas e recursos. Em casa, às vezes fico várias horas 'nerdando' em frente ao $P C$ às vezes sem propósito, jogando, navegando na internet, lendo notícias tecnológicas, e às vezes timidamente modificando códigos a partir da evolução do meu aprendizado em aula. Tento buscar fontes paralelas de conhecimento, mas me falta autodisciplina para estudar de forma mais constante e organizada." (estudante 36, masculino, 22anos, Sistemas de Informação)

Alguns estudantes citam a internet como meio de busca rápida para soluções de atividades e pesquisas acadêmicas, por meio de cópias e plágio de trabalhos que já encontram prontos.

Um estudante afirmou, por exemplo, usar " $c t r l+c e$ $c t r l+v$ para fazer trabalho mais rápido", e que a iniciativa da utilização é própria, mas justifica que tem essa iniciativa "por que se não os professores ferram o trabalho." (estudante 95, masculino, 20 anos, Ciência da Computação). Outro aluno afirma que utiliza as novas tecnologias "copiando e colando" (estudante 50, masculino, 17 anos, Sistemas de Informação), e outro para dar ctrl $+c$ e ctrl $+v$ nos trabalhos da faculdade." (estudante 62, masculino, 18 anos, curso Sistemas de Informação)

A questão do plágio, que parece ampliado pelas possibilidades de uso das tecnologias se apresenta, de modo geral como preocupação de docentes ao se defrontarem com os trabalhos acadêmicos. Esta, também, se constitui uma preocupação de pesquisadores pelos aspectos éticos envolvidos, pela consequente apropriação de ideias alheias que produz repetidores de conhecimentos e não autores críticos e criativos, o que se espera, de certo modo, de estudantes do ensino superior [15].

São, portanto, bastante variadas as atividades que os estudantes dos cursos de Ciência da Computação e de Sistemas de Informação realizam com as TIC. Nessas diversas atividades, podemos encontrar também diferentes posturas em relação aos processos de ensinoaprendizagem: desde o interesse por realizar pesquisas e fazer novas descobertas sobre os temas da área até a negação da realização das atividades acadêmicas, por meio de cópias.

Com base nos três aspectos por meio dos quais apresentamos os dados quantitativos e qualitativos produ- 
zidos pela pesquisa (tipos de tecnologias utilizadas, iniciativa na utilização das tecnologias e atividades realizadas com elas) vemos que, para os estudantes dos cursos de Ciência da Computação e Sistemas de Informação pesquisados, as TIC, em especial quando relacionadas à internet, são importantes na realização do curso. Os estudantes revelam iniciativa na utilização das TIC, e a concomitância da realização de diferentes atividades. Tais conclusões apresentam algumas possibilidades de análise sobre as TIC nos processos de ensinar e aprender do ensino superior presencial, apresentadas a seguir.

\section{Considerações finais}

Os resultados da pesquisa, apresentados anteriormente, podem ser analisados sob a ótica da teoria da relação com o saber, na perspectiva de Bernard Charlot. Alguns elementos dessa teoria contribuem, portanto, para compreender as relações entre educação e tecnologias da informação e comunicação no ensino superior presencial.

Retomamos assim a ideia de Charlot de que ninguém aprende sozinho, mas ninguém consegue ensinar se o sujeito não se mobilizar em relação à aprendizagem, e estabelecer uma relação com o saber - que também é relação com o outro e consigo mesmo - que permite a aprendizagem.

A educação é uma produção de si por si mesmo, mas essa autoprodução só é possível pela mediação do outro e com sua ajuda(...) Ninguém poderá educar me se eu não consentir, de alguma maneira, se eu não colaborar; uma educação é impossível, se o sujeito a ser educado não investe pessoalmente no processo que o educa. Inversamente, porém, eu só posso educar-me numa troca com os outros e com o mundo (...) [8]

Podemos refletir, a partir dos inventários, sobre a utilização das novas tecnologias por estudantes do ensino superior, diferenciando uma busca de informações para o atendimento a demandas colocadas pelo professor (para que ele não "ferre" o trabalho), de um movimento do sujeito mobilizado em relação ao aprender. Nos termos utilizados por Charlot, é necessário que o sujeito se engaje em uma determinada relação com o mundo que propicie a mobilização em relação ao aprender e ao saber - “... aprender enquanto modo de apropriação do mundo" [8].

Essa análise pode ser percebida em uma das respostas aos inventários de saberes: "internet neste mundo me ensina tudo, mas só aprendo o que eu quero”. (estudante 3, masculino, 17 anos, curso Ciência da Computação)

Assim, a prática docente no ensino superior passa a ser interpelada pela necessidade de auxiliar os estudantes - inclusive na utilização das TIC - na construção de uma relação com o saber adequada ao conhecimento acadêmico, que possibilite um engajamento na realização das atividades que supere a oferta de oportunidades de plágio oferecidas pelo uso das TIC.

Outra proposição teórica de Bernard Charlot que nos auxilia a analisar os dados coletados é a de que a relação com o saber é sempre - e ao mesmo tempo - epistêmica identitária e social. Ao aprender (conceitos, atitudes, práticas, valores), os sujeitos estão vivenciando processos que os levam a posicionar-se no mundo, em relação aos outros sujeitos e, também, a (re) construírem-se como sujeitos individuais. Assim, "toda relação com o saber é também relação com o outro" e "toda relação com o saber é também relação consigo próprio: através do 'aprender', (...) sempre está em jogo a construção de si mesmo e seu eco reflexivo, a imagem de si”. [8].

Os inventários de saberes mostram como a utilização das TIC constitui, para os estudantes, um elemento que estabelece marcas identitárias e sociais, por meio das quais eles falam de si mesmos:

"Eu utilizo a tecnologia na maior parte do meu dia, inclusive como ferramenta de trabalho e ainda sou difusor da mesma, pois faço instalações e manutenção de sistemas de tecnologia, portanto vivo em meio à tecnologia. No meu aprendizado não é apenas importante, é o principal fator de estar na faculdade hoje, pois preciso da tecnologia para que eu possa contribuir com o crescimento da mesma." (estudante 44, masculino, 31 anos, curso Sistemas de Informação)

"Eu me conecto ao mundo da tecnologia ao executar o meu trabalho, que é suporte técnico e manutenção de computadores, investigando e resolvendo problemas de software e hardware." (estudante 36, masculino, 34 anos, curso Sistemas de Informação)

Portanto, utilizar a TIC para pesquisar, realizar trabalhos acadêmicos, comunicar-se com seus professores e colegas - enfim, para aprender - significa, para os estudantes, estabelecer relações com os outros e consigo mesmos. Essa compreensão apresenta para a prática docente desafios e possibilidades na maneira de utilizar os recursos tecnológicos nos processos educacionais, uma vez que essa utilização envolve aspectos identitários e sociais.

Ao mobilizarmos a noção de relação com o saber proposta por Charlot para analisar a relação com o saber de 
estudantes de cursos superiores presenciais da área de computação, vemos que o aprender se estabelece em um conjunto de relações ampliadas pelas conexões com a internet: me divirto e aprendo; trabalho e aprendo; encontro-me com diferentes pessoas nas redes sociais e aprendo; pesquiso e aprendo; me conecto ao mundo e aprendo. Conclui-se, portanto, tendo como referência as respostas desses estudantes, que as tecnologias de informação e comunicação, especialmente a internet, propiciam novas relações com o saber e produzem outras práticas de estudo e outras relações com o conhecimento escolar. Essas mudanças se fazem em meio a contradições. Por um lado, o estudante não é mais dependente do conhecimento veiculado na escola através das disciplinas curriculares, mas além de responder a demandas colocadas pela escola, busca por iniciativa própria aprender. Por outro lado, o acesso à ferramenta tecnológica não garante por si só a postura necessária para o estabelecimento de uma relação com o saber que converge para a aprendizagem. Há uma multiplicidade de usos propiciada pelas tecnologias e colocadas à disposição dos estudantes que de modo autônomo podem acessá-las, ou não, ampliando ou cerceando os processos de aprendizagem. Essas possibilidades constituem, a nosso ver, desafios que precisam ser considerados nas reflexões sobre a docência no ensino superior.

\section{Referências}

[1] BELLONI, Maria. L. Educação a Distância. Campinas, SP : Associados, 1999.

[2] LÉVY, Pierre. A Inteligência Coletiva por uma antropologia do ciberespaço. São Paulo: Edições Loyola, 1998.

[3] VIGNERON, J. 1986. A Universidade Aberta e o Trabalhador Estudante. In: M. M. K., KUNSCH (org.). Comunicação e Educação Caminhos Cruzados. São Paulo, Loyola, p. 355-359.

[4] PICANÇO, A. A. Educação a distância: solução ou novos desafios? ANPED - GT Educação e Comunicação. Caxambu, MG, 2001.

[5] LITTO, F. M.e FORMIGA, M. (orgs). Educação a distância: o estado da arte. São Paulo: Pearson Education do Brasil, 2009.

[6] CHARLOT, Bernard. Rapport au savoir en milieu populaire. Une recherche dans les lycées professionnels de banlieue. Paris: Anthropos, 1999.

[7] CHARLOT, Bernard. Da Relação com o Saber: Elementos para uma teoria. Artmed, 2000.
[8] CHARLOT, Bernard (Org.). Os jovens e o saber: perspectivas mundiais. Porto Alegre: Artmed Editora, 2001.

[9] CHARLOT, Bernard. Relação com o saber: Formação dos professores e globalização. Questões para a educação hoje. Porto Alegre: Artmed, 2005.

[10] BICALHO, Maria Gabriela Parenti. Ensino Superior Privado, Relação com o saber e Reconstrução Identitária. 290f. Tese (doutorado em Educação). Faculdade de Educação. Universidade Federal de Minas Gerais. 2004.

[11] BICALHO, Maria Gabriela Parenti. Relação com o saber e processos de construção do eu epistêmico por estudantes de pedagogia de universidades privadas. In: Reunião Anual da Associação Nacional de Pesquisa e Pós-Graduação em Educação - ANPED, 33, 2010. Caxambu. Disponível em http://www.anped.org.br/33encontro/internas/ver/trab alhos-gt14

[12] BICALHO, Maria Gabriela Parenti. Relação com o saber e processos de construção do eu epistêmico por estudantes de pedagogia de universidades privadas. In CHARLOT, Bernard. (org.). Juventude Popular e Universidade: Acesso e Permanência. São Cristovão: Editora da UFS, 2011.

[13] SOUZA, Maria Celeste Reis Fernandes de. Relação com o saber e ensino superior: um estudo sobre estudantes do ensino superior privado. 33a Reunião Anual da ANPEd. Educação no Brasil: o balanço de uma década. Caxambu, 2010.

[14] MALTEMPI, Marcus Vinicius. Construcionismo: pano de fundo para pesquisas em informática aplicada à educação. In: BICUDO, Maria Aparecida Viggiani; BORBA, Marcelo de Carvalho. Educação Matemática: pesquisa em movimento. São Paulo: Cortez, 2004, p. 264-282.

[15] SILVA, Obdália Santana Ferraz. Entre o plágio e a autoria: qual o papel da universidade? In: Revista Brasileira de Educação, v. 13, n. 38, p. 357-368, maio/ago. 2008.

[16] LÉVY, Pierre. Cibercultura. 2. ed. São Paulo : Quiron: Ed. 34, 2000. 260 p.

[17] LÉVY, Pierre. A inteligência coletiva: por uma antropologia do ciberespaço. 2. ed. São Paulo : Quiron: Loyola, 1999. 
[18] BICUDO, Maria Aparecida Viggiani; BORBA, Marcelo de Carvalho. Educação Matemática: pesquisa em movimento. São Paulo: Cortez, 2004.

[19] AMEM, Bernadete Malmegrim Vanzella; NUNES, Lena Cardoso. Tecnologias de Informação e Comunicação: contribuições para o processo interdisciplinar no ensino superior. Rev. bras. educ. med., Rio de Janeiro, v. 30, n. 3, dez. 2006 . Disponível em $<$ http://www.scielo.br/scielo.

[20] COSTA, Priscila Berenice et al . Fluência digital e uso de ambientes virtuais: caracterização de alunos de enfermagem. Rev. esc. enferm. USP, São Paulo, v. 45, n. spe, dez. 2011. Disponível em http://www.scielo.br/scielo

[21] PERES, Heloisa Helena Ciqueto et al . Estudo exploratório sobre a utilização dos recursos de informática por alunos do curso de graduação em enfermagem. Rev. esc. enferm. USP, São Paulo, v. 35, n. 1, mar. 2001. Disponível em http://www.scielo.br/scielo.

[22] PERES, Heloisa Helena Ciqueto; MEIRA, Karina Cardoso; LEITE, Maria Madalena Januário. Ensino de didática em enfermagem mediado pelo computador: avaliação discente. Rev. esc. enferm. USP, São Paulo, v. 41, n. 2, jun. 2007 . Disponível em http://www.scielo.br/scielo.

[23] SANTA-ROSA José Guilherme; STRUCHINER, Miriam. Tecnologia educacional no contexto do ensino de histologia: pesquisa e desenvolvimento de um ambiente virtual de ensino e aprendizagem. Rev. bras. educ. med., Rio de Janeiro, v. 35, n. 2, jun. 2011. Disponível em http://www.scielo.br/scielo. 